University of Nebraska - Lincoln

DigitalCommons@University of Nebraska - Lincoln

2006

\title{
Adsorption of Uranyl on Gibbsite: A Time-Resolved Laser-Induced Fluorescence Spectroscopy Study
}

Hyun-Shik Chang

University of Washington, Korshin@u.washington.edu

Gregory Korshin

University of Washington

Zheming Wang

Pacific Northwest National Laboratory, Zheming.wang@pnl.gov

John M. Zachara

Pacific Northwest National Laboratory, john.zachara@pnl.gov

Follow this and additional works at: https://digitalcommons.unl.edu/usdoepub

Part of the Bioresource and Agricultural Engineering Commons

Chang, Hyun-Shik; Korshin, Gregory; Wang, Zheming; and Zachara, John M., "Adsorption of Uranyl on Gibbsite: A Time-Resolved Laser-Induced Fluorescence Spectroscopy Study" (2006). US Department of Energy Publications. 230.

https://digitalcommons.unl.edu/usdoepub/230

This Article is brought to you for free and open access by the U.S. Department of Energy at DigitalCommons@University of Nebraska - Lincoln. It has been accepted for inclusion in US Department of Energy Publications by an authorized administrator of DigitalCommons@University of Nebraska - Lincoln. 


\section{Adsorption of Uranyl on Gibbsite: A Time-Resolved Laser-Induced Fluorescence Spectroscopy Study}

HYUN-SHIK CHANG , ${ }^{\dagger}$

GREGORY V. KORSHIN, $*,+$

ZHEMING WANG, W AND $^{\circ}$

J O H M. ZACHARA

Department of Civil and Environmental Engineering,

Box 352700, University of Washington, Seattle, Washington 98115-2700, and Pacific Northwest National Laboratory, P.O. Box 999/MS K8-96, Richland, Washington 99352

Uranyl adsorbed on gibbsite at $\mathrm{pH} 4.0-8.0$ and ionic strengths (ISs) $0.001-0.4 \mathrm{M}\left(\mathrm{NaClO}_{4}\right)$ in the absence of carbonate was studied using time-resolved laser-induced fluorescence spectroscopy (TRLIFS) under cryogenic conditions. TRLIFS data showed the presence of several distinct emission components. Their contributions were determined using the evolving factor analysis approach. Four components denoted as species $A, B, C$, and D were discerned. Each of them was characterized by a characteristic response to $\mathrm{pH}$ and IS changes and also by a unique combination of the values of the fundamental transition energy $E_{0,0}$, vibronic spacing $\Delta E$, and half-width of the vibronic lines $\Delta W$. Species $A$ and $B$ were major contributors to the overall emission. They were mainly affected by the $\mathrm{pH}$ and predominated below and above $\mathrm{pH} 5.0$, respectively. In contrast with that, the contribution of species $\mathrm{C}$ was noticeable only at IS $=0.001 \mathrm{M}$, while it was suppressed or absent at high IS values. It was concluded that species $A$ and $B$ are likely to correspond to inner-sphere surface aluminol complexes $\equiv \mathrm{AlO}-\left(\mathrm{UO}_{2}\right)^{+}$and $\equiv \mathrm{AIO}-$ $\left(\mathrm{UO}_{2}\right) \mathrm{OH}^{\circ}$, while species $\mathrm{C}$ was hypothesized to correspond to electrostatically bound uranyl complexes (predominantly $\left[\mathrm{UO}_{2}(\mathrm{OH})_{3}\right]^{-}$.

\section{Introduction}

Migration of uranium (predominated in oxic conditions by uranyl $\left(\mathrm{UO}_{2}{ }^{2+}\right)$ and its hydroxo and carbonate complexes) in the subsurface zone can be quantified either on the basis of calculations of an apparent distribution coefficient $K_{\mathrm{d}}$ applicable to a particular set of environmental conditions or using more specific adsorption models $(1-12)$. The modeling approach reproduces most conspicuous trends, notably the adsorption edge at $\mathrm{pH}>4$ that characterizes the adsorption of uranyl on subsurface minerals. However, model optimization can be carried out with equal success using diverging assumptions concerning the identities of surface species. For instance, modeling of uranium adsorption on oxyhydroxides, alumosilicates, silica, and gibbsite has been carried out assuming the existence of both monomeric and trimeric surface species of uranyl $(5-12)$, while in other

* Corresponding author phone: (206) 543-2394; fax: (206) 6859185; e-mail: Korshin@u.washington.edu.

University of Washington.

₹ Pacific Northwest National Laboratory. studies only monomeric species were hypothesized to exist $(9,13,14)$.

Ideally, the development of intrinsically constrained adsorption models should be based on independent evidence concerning the identities of adsorbed uranyl species. This can be achieved on the basis of the results of methods such as EXAFS and/or rime-resolved laser-induced fluorescence spectroscopy (TRLIFS). EXAFS has been successfully used to ascertain the structure of the inner complexation shell of uranyl adsorbed on several representative solids (13, 1517). Despite its sensitivity to the types/numbers of nearest neighbors around the $\mathrm{UO}_{2}{ }^{2+}$ ion and radial distances between them, EXAFS needs to employ relatively high uranyl loadings and has difficulties in separating contributions of nonidentical complexation shells. TRLIFS, on the other hand, is very sensitive to the presence of dissimilar $\mathrm{UO}_{2}{ }^{2+}$ species. TRLIFS spectra of mononuclear uranyl species tend to be characterized by several well-resolved vibronic lines. A vibronic sequence can be characterized by the fundamental transition energy $E_{0,0}$ that corresponds to the vibronic line with the highest energy and the value of the vibronic spacing $\Delta E$ between the adjacent emission lines $(10,11,18-23)$. For a well-resolved TRLIFS spectrum of a single uranyl species, the $\Delta E$ value is determined by the difference between vibrational energy levels of the symmetric stretching mode of the linear $(\mathrm{O}=\mathrm{U}=\mathrm{O})^{2+}$ ion in its ground state. $E_{0,0}$ and $\Delta E$ values for various uranyl species, as well as their quantum yields and fluorescence lifetimes, have been shown to be sensitive to the composition and structural organization of the local chemical environment $(10-12,22-28)$.

TRLIFS studies of adsorbed uranyl invariably indicate the presence of two or more surface species (10-12, 29-35). For instance, TRLIFS studies of uranyl adsorbed on montmorillonite showed the presence of four species denoted as $S_{1}$ to $S_{4}(10)$. Species $S_{1}$ and $S_{2}$ were assigned to uranyl bound at aluminol sites via inner-sphere complexation and at ion exchange sites, respectively. The featureless spectrum of species $S_{3}$ was concluded to correspond to oligomeric uranyl complexes formed at high surface coverages, and species $\mathrm{S}_{4}$ was assigned to an outer-sphere electrostatically bound complex of uranyl. Although the spectrum of species $\mathrm{S}_{4}$ was visually similar to that of free $\mathrm{UO}_{2}{ }^{2+}, \mathrm{S}_{4}$ was associated with $\mathrm{UO}_{2}(\mathrm{OH})^{+}$or other hydrolyzed uranyl species. For gibbsite, two species of adsorbed uranyl with widely different fluorescence lifetimes but similar vibronic spectra were discerned at ambient temperature (35). The emission spectra with the short and fluorescence long lifetimes were hypothesized to correspond to an inner-sphere mononuclear complex and polynuclear uranyl surface species, respectively.

A more quantitative approach was employed in ref 32 , where the spectra of uranyl adsorbed on silica were processed using evolving factor analysis (EFA) to determine the contributions of dissimilar emitters. On the basis of the TRLIFS and EFA data, it was concluded that the emitting species were surface complexes $\equiv \mathrm{SiO}_{2}-\left(\mathrm{UO}_{2}\right)^{0}$ and $\equiv \mathrm{SiO}_{2}-\left(\mathrm{UO}_{2}\right) \mathrm{OH}^{-}$dominating at $\mathrm{pH} \leq 5.5$ and in the range between 5.5 and 8.0, respectively. It was also hypothesized that a third nonfluorescing species, $\equiv \mathrm{SiO}_{2}-\left(\mathrm{UO}_{2}\right) \mathrm{OHCO}_{3}{ }^{3-}$, existed in the $\mathrm{pH}$ range $8-9$.

These results indicate that TRLIFS can provide in situ information about the nature of adsorbed uranyl species and their response to variations of water chemistry parameters. The principal goal of this study was to utilize these strengths of the TRLIFS technique and to gain better understanding of interactions between uranyl and the surface of gibbsite, a model phase representative of the properties 
of many minerals that control the mobility of uranium and other metals in the subsurface zone.

\section{Experimental Section}

Gibbsite purchased from Alkan (SF4 lot no. 00617111) was pretreated using procedures described in the Supporting Information. A stock suspension of the purified gibbsite was prepared by suspending the solid in $0.01 \mathrm{M} \mathrm{NaClO}_{4}$ at $\mathrm{pH}$ 7.1. In accord with BET measurements reported in refs 7 and 8 , the specific surface area of the gibbsite was $3.5 \mathrm{~m}^{2} / \mathrm{g}$.

Adsorption experiments were conducted in the $\mathrm{pH}$ range 4.0-9.0 at ionic strengths $0.001,0.1$, and $0.4 \mathrm{M} \mathrm{NaClO}_{4}$. The total concentration of uranyl in the suspensions was $8.4 \times$ $10^{-7} \mathrm{M}$. All sorption experiments were carried out under nitrogen. The samples were allowed to equilibrate for a week. At the end of the equilibration period, the samples were centrifuged to separate the supernatant and the solid phase, which was transferred into $2 \mathrm{~mm} \times 4 \mathrm{~mm}$ (i.d.) quartz cuvettes for TRLIFS measurements performed at $5.0 \pm 0.5 \mathrm{~K}$. The fluorescence spectra were obtained by excitation into the first strong absorption band of the uranyl ion at $415 \mathrm{~nm}$ (36) using a Spectra-Physics MOPO-730 laser. The fluorescence was collected at $90^{\circ}$ to the excitation beam into the entrance slit of an Acton SpectroPro 300i double-monochromator spectrograph. A $460 \mathrm{~nm}$ cutoff filter was used to reject the scattered laser light. A Princeton Instruments PIMAX timegated CCD camera controlled by WinSpec software was used to acquire the spectra. Other details concerning the experimental setup are provided in the Supporting Information and in refs 33 and 34 .

TRLIF spectra of uranyl were recorded using a $100 \mu$ s gate width and varying delay times and analyzed using EFA. EFA was performed to determine the number of independent components, while multivariate curve resolution (MCR) was used to obtain their respective emission spectra. EFA and MCR calculations were carried out using PLS Toolbox and Matlab software. The quality of the deconvolution was optimized using the least-squares method and confirmed by visual inspection of the resulting spectra. The EFA/MCR analysis allowed obtaining a limited number of independent spectra that fit reasonably well all the experimental TRLIFS data obtained at widely varying $\mathrm{pH}$ values, ionic strengths, and delay times. The deconvoluted spectra were processed using Gaussian peak analysis (GPA) with PeakFit software. To improve the quality of GPA, the numerical noise was reduced with a sixth-order Savitzky-Golay algorithm. The deconvoluted emission spectra were accepted until the value of the correlation coefficient $r^{2}$ was above 0.9 .

\section{Results}

TRLIFS spectra of uranyl adsorbed on gibbsite comprised five or six vibronic bands with varying intensities and levels of resolution. For instance, at pH 7.5 and ionic strength 0.001 $\mathrm{M}$ the emission spectra exhibited a relatively weak band at $482 \mathrm{~nm}$ followed by well-resolved vibronic peaks with maxima at $497.4,516.5,538.8$, and $564.0 \mathrm{~nm}$ (Figure 1) and a broad band at $596 \mathrm{~nm}$. At increased delay times, the intensity of the vibronic line located at $482 \mathrm{~nm}$ increased, while the maxima of all other lines exhibited a red shift. At the longest delay time utilized in this study (1205 $\mu \mathrm{s})$, the maxima of the four most intense vibronic lines were located at 502.9, 522.8, 544.8, and $569.6 \mathrm{~nm}$.

Variations of $\mathrm{pH}$ and ionic strength were associated with pronounced changes in the TRILFS spectra. For instance, the intensity of the vibronic line at $482 \mathrm{~nm}$ increased with $\mathrm{pH}$ at $0.001 \mathrm{M}$ ionic strength as shown in Figure 2 (only the data for $\lambda<515 \mathrm{~nm}$ are shown in that figure for clarity), but at $\mathrm{pH}>8.0$ it disappeared. All remaining vibronic lines exhibited a red shift and broadened as the $\mathrm{pH}$ increased. A

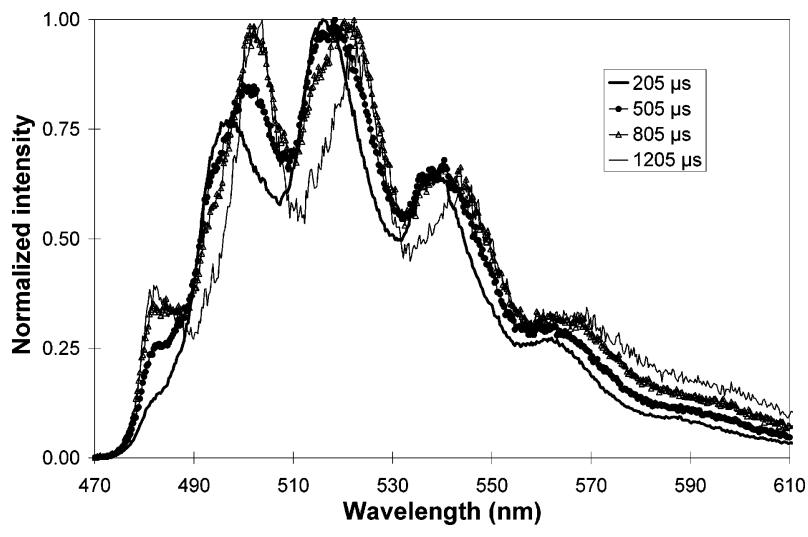

FIGURE 1. TRLIFS of uranyl adsorbed on gibbsite at different delay times (gate width $100 \mu \mathrm{s}$, ionic strength $0.001 \mathrm{M}$, pH 7.5).

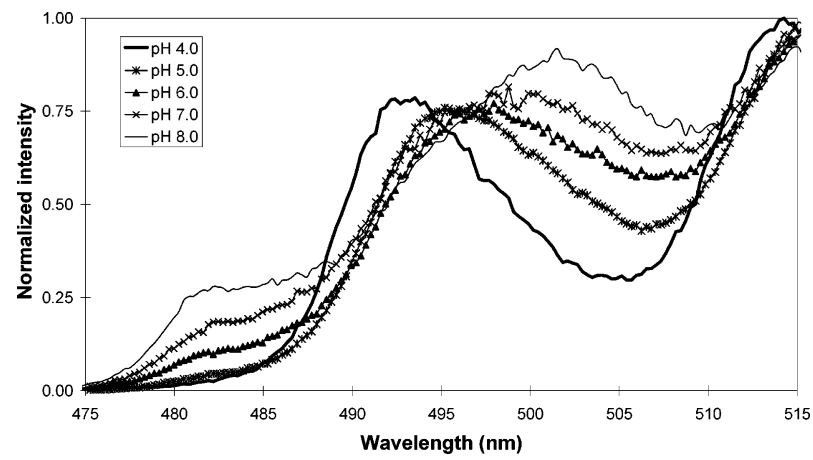

FIGURE 2. Effects of pH on TRILFS spectra of uranyl adsorbed on

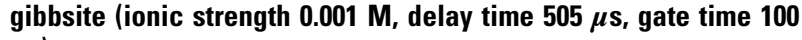
$\mu \mathrm{s})$.

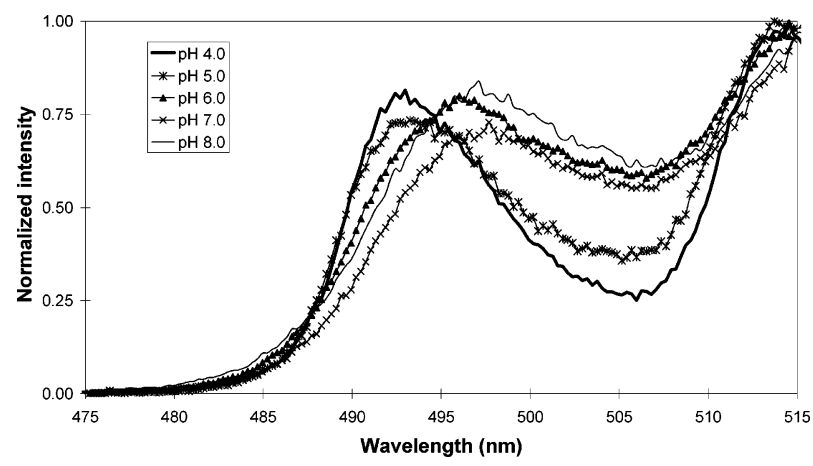

FIGURE 3. Effects of pH on TRILFS spectra of uranyl adsorbed on gibbsite (ionic strength $0.4 \mathrm{M}$, delay time $505 \mu \mathrm{s}$, gate time $100 \mu \mathrm{s}$ ).

similar red shift and broadening of the vibronic lines located between 500 and $580 \mathrm{~nm}$ was observed at increased $\mathrm{pH}$ values and ionic strengths 0.1 and $0.4 \mathrm{M}$. However, the intensity of the vibronic line at $482 \mathrm{~nm}$ was much less at a $0.1 \mathrm{M}$ ionic strength than at IS $=0.001 \mathrm{M}$. At IS $=0.4 \mathrm{M}$, it was practically absent (Figure 3).

These observations indicated that the TRLIFS spectra described above contain components that are sensitive to variations of $\mathrm{pH}$ and ionic strength. To determine their characteristics, the TRLIFS spectra recorded at varying $\mathrm{pH}$ values and ionic strengths were processed using EFA and MCR. They showed that the observed changes in the TRLIFS spectra of gibbsite-adsorbed uranyl could be explained by the presence of four emitters, each characterized by its distinct vibronic sequence and specific response to $\mathrm{pH}$ and ionic strength variations. For the purposes of discussion, these components will be referred to as species A, B, C, and $D$. Their emission spectra (normalized by the intensity of the most prominent vibronic line) are shown in Figure 4, while 

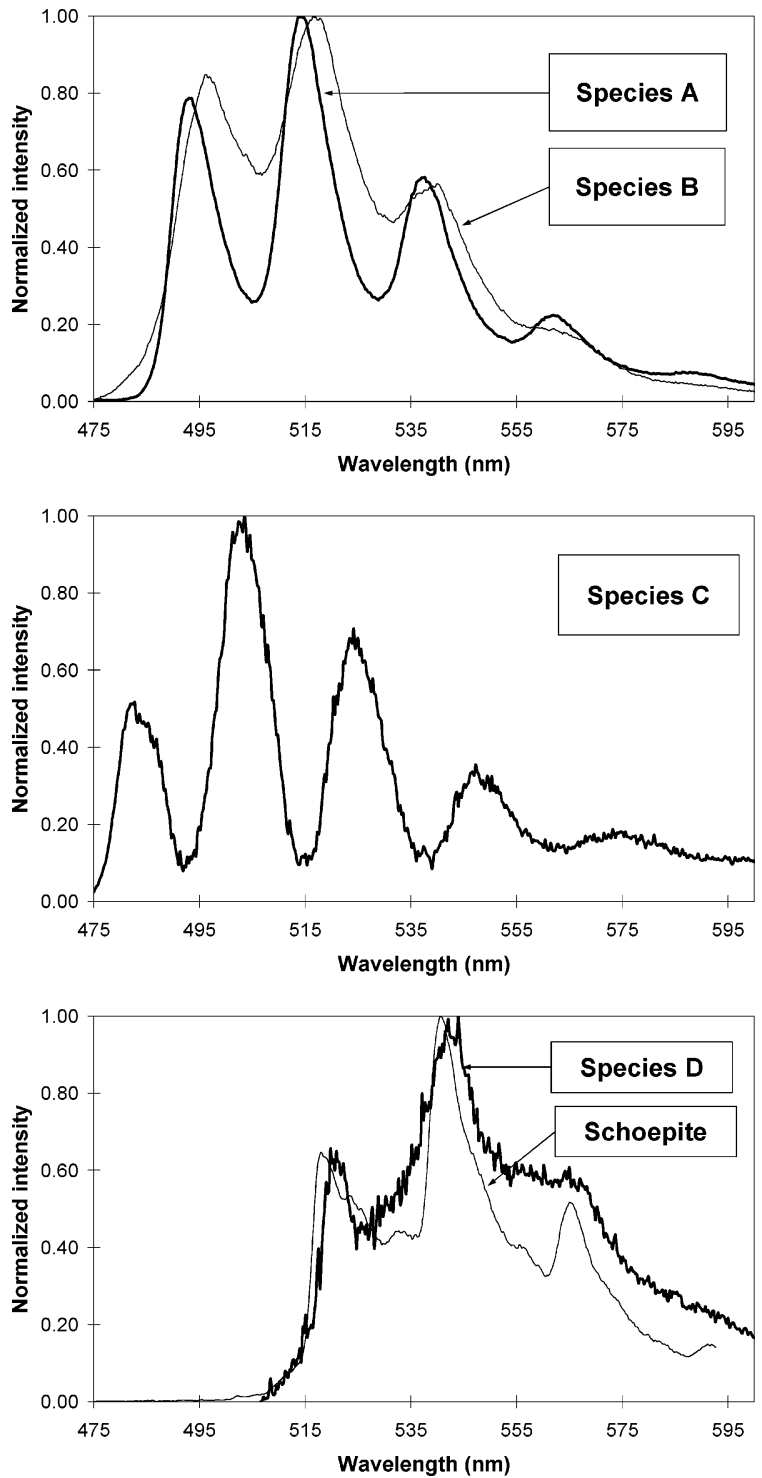

FIGURE 4. Comparison of normalized emission spectra of species $A, B, C$, and D obtained by deconvolution of TRLIFS spectra of uranyl adsorbed on gibbsite at varying $\mathrm{pH}$ values and ionic strengths.

\section{TABLE 1. Spectroscopic Parameters of the Emission Spectra of Species of Uranyl Adsorbed on Gibbsite}

$\begin{array}{cccc}\text { species } & E_{0,0}\left(\mathbf{c m}^{-1}\right) & \Delta E\left(\mathbf{c m}^{-1}\right) & \Delta W\left(\mathbf{c m}^{-1}\right) \\ \text { A } & 20260 & 820 \pm 22 & 492 \pm 51 \\ \text { B } & 20130 & 760 \pm 21 & 606 \pm 25 \\ \text { C } & 20670 & 805 \pm 16 & 417 \pm 16\end{array}$

the values of the fundamental transition energies $E_{0,0}$ (determined similarly to those in refs 10 and 11 as the energies of the first well-resolved vibronic lines), average vibronic spacings $\Delta E$, and Gaussian half-widths of the vibronic lines $\Delta W$ are listed in Table 1 . The values of $\Delta E$ and $\Delta W$ were determined via Gaussian deconvolution of the normalized spectra of species A, B, and C and averaged for the first three vibronic lines that had the best resolution.

The effects of $\mathrm{pH}$ and ionic strength on the relative contributions of species A, B, C, and D to the total normalized emission are shown in Figure 5. It is to be noted that since the quantum yields $\phi$ of the emission of species A, B, C, and $\mathrm{D}$ are not known, the contributions of the EFA-discerned species to the emission cannot be equated with their actual concentrations.
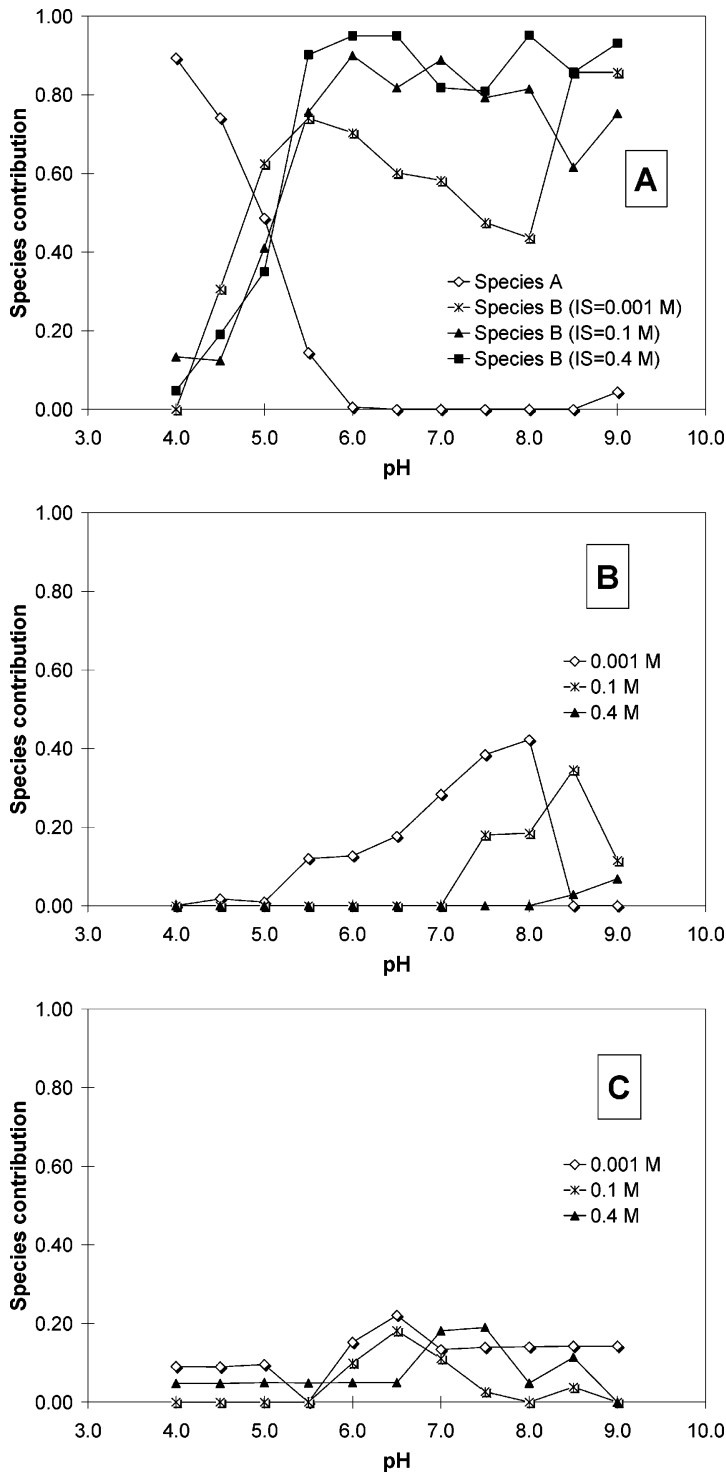

FIGURE 5. Effects of $\mathrm{pH}$ and ionic strength on the relative contributions of (A) species A and B, (B) species $C$, and (C) species $D$ in the TRLIFS spectra of uranyl adsorbed on gibbsite.

The spectra of these species and their behavior had the following features. The contributions of species A and B were affected by the variations of $\mathrm{pH}$ and to a small extent by IS at $\mathrm{pH}<6$. Species A dominated at $\mathrm{pH}<5.0$. The contribution of species B at pH 4.0 was small, albeit nonnegligible (ca. $6 \%$ contribution to the normalized emission intensity), and increased rapidly with the $\mathrm{pH}$ (Figure 5A). At $\mathrm{pH}>6$, the contribution of species B was almost constant, although at IS $=0.001 \mathrm{M}$ its contribution exhibited a gradual decrease from $\mathrm{pH} 5.5$ to $\mathrm{pH} 8.0$ followed by a sharp increase from $\mathrm{pH}$ 8.0 to $\mathrm{pH} 9.0$. As will be discussed below, these changes are the results of the presence of species $\mathrm{C}$.

The relative contribution of species A in the TRLIFS spectra decreased as the delay time increased, indicating that the fluorescence lifetime of species A was shorter than that of species B. Compared to those of species A, the vibronic lines of species B were broader $\left(\Delta W\right.$ values of 492 and $606 \mathrm{~cm}^{-1}$ for species $A$ and $B$, respectively) and red-shifted with values of the fundamental transition energies $E_{0,0}$ of 20130 and 20260 $\mathrm{cm}^{-1}$, respectively (Table 1, Figure $4 \mathrm{~A}$ ). The vibronic spacings for species A and B were also different $\left(820\right.$ and $760 \mathrm{~cm}^{-1}$, respectively).

The emission spectrum of species $\mathrm{C}$ and its dependence on the $\mathrm{pH}$ and ionic strength were markedly different from 
those for species A and B (Figures 4 and 5B). The vibronic bands in the spectrum of species $C$ were very well resolved and exhibited a considerable blue shift of the fundamental transition energy $\left(E_{0,0}=20670 \mathrm{~cm}^{-1}\right)$. The vibronic spacing $\left(815 \mathrm{~cm}^{-1}\right)$ of species $C$ was larger than that of species $A$ and close to that of species $\mathrm{B}$. The vibronic lines in the spectrum of species $\mathrm{C}$ were much narrower $\left(\Delta W=417 \mathrm{~cm}^{-1}\right)$ than those in the spectra of species A and B.

The presence of species $\mathrm{C}$ was most prominent for IS = $0.001 \mathrm{M}$ (Figure 5B). At that ionic strength, the contribution of species $\mathrm{C}$ was zero at $\mathrm{pH} 4.0$ and increased with the $\mathrm{pH}$, reaching a maximum ( $42 \%$ contribution to the total emission measured at an $804 \mu$ s delay time) at 8.0. At a $0.1 \mathrm{M}$ ionic strength, species $\mathrm{C}$ was absent in the $\mathrm{pH}$ range $4.0-7.0$ and became measurable above $\mathrm{pH} 7.0$, although its contribution was much smaller than that at IS $=0.001 \mathrm{M}$. For IS $=0.4 \mathrm{M}$, species $\mathrm{C}$ was essentially absent, albeit a very weak contribution of it could tentatively be detected at $\mathrm{pH}>8.0$.

The spectrum of species D lacked resolved vibronic lines (Figure 4C), and its contribution to the overall emission spectra was lower than that of the three other species. Due to the lack of well-resolved vibronic lines, Gaussian deconvolution of the emission spectrum of species D was not carried out.

\section{Discussion}

The data presented above can be used to explore the identities of the species that contribute to the emission of uranyl adsorbed on gibbsite. The analysis can begin with the examination of the likely natures of species A and B, which were predominant at $\mathrm{pH}$ values below and above 5.5, respectively, and little affected by IS variations. Both the existence of a well-defined $\mathrm{pH}$ threshold that corresponds to the transition of species A to species B and the properties of their vibronic sequences indicate that these species are likely to be associated with the protonated and deprotonated forms of a mononuclear uranyl complex. Indeed, the values of the fundamental transition energy and vibronic spacing for species B are less than those of species A (Table 1), while the apparent emission lifetime of species $B$ is higher than that of species A. These changes are similar to those observed for hydroxo complexes of uranyl in aqueous solutions. The data of TRLIFS and Raman spectroscopy show that formation of hydroxo complexes ranging from $\left[\mathrm{UO}_{2}(\mathrm{OH})\right]^{+}$to $\left[\mathrm{UO}_{2}(\mathrm{OH})_{4}\right]^{2-}$ is accompanied by a monotonic decrease of the corresponding $E_{0,0}$ and $\Delta E$ values, a broadening of the vibronic lines, and an increase of the lifetimes of the relevant hydroxo complexes $(10,11,22-27,37)$. The good resolution of the vibronic lines in the TRLIF spectra of species A and $\mathrm{B}$ also indicates that they are unlikely to be polynuclear compounds. This is because the presence of multiple vibration modes in the interacting $(\mathrm{O}=\mathrm{U}=\mathrm{O})^{2+}$ structures in polynuclear $\mathrm{UO}_{2}{ }^{2+}$ complexes yields an increased number of vibronic lines, thus potentially making the resulting spectra more convoluted compared to those of mononuclear $\mathrm{UO}_{2}{ }^{2+}$ species $(10,11,23,25,37)$. On the basis of this reasoning and in agreement with the data of prior research $(7-9,35)$ that has provided evidence that predominant $\mathrm{pH}$-dependent forms of gibbsite-adsorbed uranyl are associated with aluminol sites and can be denoted as $\equiv \mathrm{AlO}-\left(\mathrm{UO}_{2}\right)^{+}$and $\equiv \mathrm{AlO}-\left(\mathrm{UO}_{2}\right) \mathrm{OH}^{\circ}$, respectively, we hypothesize that species $\mathrm{A}$ and $\mathrm{B}$ correspond to these mononuclear surface complexes.

The behavior of species $\mathrm{C}$ points to a different nature of this emitter. It is sensitive to both $\mathrm{pH}$ and IS variations, and has highly resolved and narrow vibronic lines in its spectrum, which blue-shifted compared with those in the spectra of species A and B. These properties of species $\mathrm{C}$ are similar to those of species $\mathrm{S}_{4}$ described in ref 10 for the $\mathrm{UO}_{2}{ }^{2+}$ / montmorillonite system and associated there with electrostatically bound uranyl. On the basis of these comparisons,

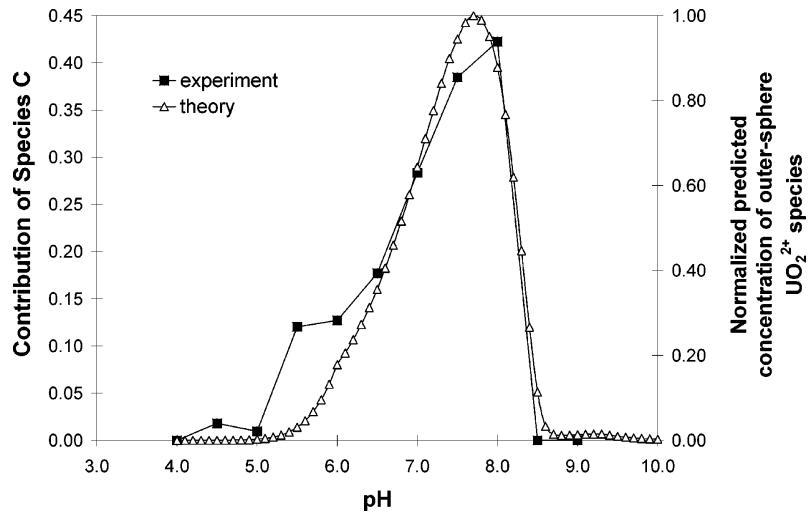

FIGURE 6. Comparison of experimental and predicted profiles of total uranyl adsorbed via outer-sphere complexation on the surface of gibbsite at ionic strength $0.001 \mathrm{M}$. The point of zero charge was set at pH 8.6.

it was hypothesized that species $\mathrm{C}$ corresponds to electrostatically adsorbed $\mathrm{UO}_{2}{ }^{2+}$.

To examine this hypothesis in more detail, we performed semiquantitative analysis of the IS and $\mathrm{pH}$ effects on the amount and speciation of uranyl attracted to the surface via electrostatic interactions. To carry out such modeling, literature data on the charge of the surface of gibbsite $(\sigma)$ as a function of $\mathrm{pH}$ and IS $(38,39)$ were used to calculate the values of the electrostatic potential $(\Psi)$ in the diffuse part of the EDL. The calculations utilized the Gouy-Chapman formula for a 1,1-electrolyte at $20{ }^{\circ} \mathrm{C}(40,41)$ :

$$
\sigma=0.1174 I^{1 / 2} \sinh (19.46 \Psi)
$$

where $I$ is the ionic strength. The value of the point of zero charge (pzc) for gibbsite in these calculations was set at 8.6 (38-40). The obtained $\Psi$ values were used to calculate the speciation of the uranyl in the diffuse part of the EDL. To do so, the speciation of uranyl in the aqueous phase was calculated using the recently reviewed formation constants for uranyl complexes compiled in MINTEQA2 and ref 42. The speciation and the relative abundances of the nearsurface uranyl species were then calculated using the following equation, which quantifies electrostatic interactions between the surface with a $\Psi$ potential and species with charges $Z_{i}$ :

$$
S_{i}=\frac{C_{i} \exp \left(Z_{i} \Psi F / R T\right)}{\sum_{i} C_{i} \exp \left(Z_{i} \Psi F / R T\right)}
$$

In eq $2, S_{i}$ is the contribution of species $i$ to the total uranyl electrostatically attracted to the surface, while $Z_{i}$ and $C_{i}$ and are its charge and equilibrium concentration in the aqueous phase.

These calculations are semiquantitative because they do not take into account the total mass balance for the uranyl solutes and adsorbed species. Despite this limitation, the approach can be used to examine the trends in the speciation of electrostatically adsorbed uranyl species and their correlations with the TRLIFS evidence for species $\mathrm{C}$. The results of calculations carried out using eqs 1 and 2 and equilibrium $\mathrm{UO}_{2}{ }^{2+}$ speciation constants compiled in ref 42 showed that at IS $=0.001 \mathrm{M}$ the relative amount of $\mathrm{UO}_{2}{ }^{2+}$ species adsorbed via electrostatic interactions was predicted to be close to zero at $\mathrm{pH}<6.0$ (Figure 6). It increased at higher $\mathrm{pH}$ values and reached a maximum at $\mathrm{pH}$ 7.8. At $\mathrm{pH}>8.0$, the amount of electrostatically adsorbed uranyl was predicted to decrease 
precipitously due to the low charge of the surface and reversal of its sign at $\mathrm{pH}>8.6$.

The actual behavior of species $\mathrm{C}$ at IS $=0.001 \mathrm{M}$ was similar to that predicted by the modeling (Figure 6). Specifically, the sharp decrease of the emission of species $\mathrm{C}$ at $\mathrm{pH}>8.0$ was in close agreement with the model calculations, although the diminishment of the contribution of species $\mathrm{C}$ at $\mathrm{pH}<6.0$ was not as rapid as predicted theoretically. Analysis of the speciation of uranyl adsorbed via outer-sphere interactions and calculated for IS $=0.001$ $\mathrm{M}$ showed that $\mathrm{UO}_{2}{ }^{2+}$ speciation in the EDL is different from that in the aqueous phase (Figure S2 in the Supporting Information). At $\mathrm{pH}<8$, free uranyl, $\left[\mathrm{UO}_{2}(\mathrm{OH})\right]^{+}$, $\left[\mathrm{UO}_{2}(\mathrm{OH})_{2}\right]^{0}$, and $\left[\left(\mathrm{UO}_{2}\right)_{3}(\mathrm{OH})_{5}\right]^{+}$are expected to predominate in the bulk solution, while in the EDL $\left[\mathrm{UO}_{2}(\mathrm{OH})_{3}\right]^{-}$is the absolutely predominant species. The conclusion concerning the predominance of $\left[\mathrm{UO}_{2}(\mathrm{OH})_{3}\right]^{-}$in the EDL is additionally supported by the fact that the experimentally measured value of the vibronic spacing for $\left[\mathrm{UO}_{2}(\mathrm{OH})_{3}\right]^{-}$was close to 790 $\mathrm{cm}^{-1}$ (22), while our measurements yielded $805 \mathrm{~cm}^{-1}$.

At IS $=0.1 \mathrm{M}$, the values of $\Psi$ are depressed and the effects of the $\Psi$ changes on the uranyl speciation in the EDL were predicted to be less abrupt (Figures S1 and S2 in the Supporting Information). The actual behavior of species $\mathrm{C}$ was comparable with the theoretical predictions, although the agreement between them was not nearly as close as that for IS $=0.001 \mathrm{M}$. The model also predicted that, compared to that for IS $=0.001 \mathrm{M}$, the contribution of species C at IS $=0.1 \mathrm{M}$ should decrease by more than an order of magnitude. The experimental results were generally consistent with these predictions, although the observed decrease of the contribution of species $\mathrm{C}$ at $\mathrm{IS}=0.1 \mathrm{M}$ was less then predicted.

In contrast with that of species $\mathrm{A}, \mathrm{B}$, and $\mathrm{C}$, the resolution of the emission spectrum of species $D$ was poor. Nonetheless, it was observed that the main features of the emission of schoepite, for instance, the location of the first vibronic line and the overall shape of the emission envelope, were similar to those of species D (Figure 4). On that basis, a conclusion was made that the emission attributed to species D is likely to be a manifestation of the presence of schoepite, which in accord with uranyl equilibrium calculations could precipitate at $\mathrm{pH}>6.1$, where the contribution of species $\mathrm{D}$ is more pronounced. The nonzero contributions of species D observed for $\mathrm{pH}<6.1$ are likely to be an artifact of numerical deconvolution.

In summary, the results of this study indicate that TRLIFS in combination with EFA can be used to detect and separate the contributions of inner-sphere and electrostatically bound uranyl complexes for model systems such as gibbsite, and quantify $\mathrm{pH}$ and ionic strength effects on them. The inherent sensitivity of TRLIFS to the presence of dissimilar uranyl emitters allows in principle exploration of substrateadsorbate interactions for other, potentially more complex systems that involve the sorption and/or aquatic speciation of uranyl and allied elements.

\section{Acknowledgments}

G.K. and H.-S.K. acknowledge Pacific Northwest National Laboratory (PNNL) and the Interfacial and Condensed Phase Chemical Physical Summer Research Institute at PNNL for support of this study. This project was supported by the Hanford Remediation and Closure Science Project, and by the Environmental Management Sciences Program (EMSP) managed by the U.S. Department of Energy (DOE) Office of Biological and Environmental Research (OBER). The fluorescence measurements were performed at the W.R. Wiley Environmental Molecular Sciences Laboratory, a national scientific user facility sponsored by the U.S. DOE OBER and located at PNNL. PNNL is operated for the Department of Energy by Battelle.

\section{Supporting Information Available}

A detailed description of the experimental procedures and equipment, two additional figures that show the results of calculations of uranyl speciation, and a list of all equilibrium constants used in the calculations. This material is available free of charge via the Internet at http://pubs.acs.org.

\section{Literature Cited}

(1) Kohler, M.; Curtis, G. P.; Meece, D. E.; Davis, J. A. Methods for estimating adsorbed uranium (VI) and distribution coefficients of contaminated sediments. Environ. Sci. Technol. 2004, 38 (1), 240-247.

(2) Prikryl, J. D.; Jain, A.; Turner, D. R.; Pabalan, R. T. Uranium (VI) sorption behavior on silicate mineral surfaces. J. Contam. Hydrol. 2001, 47 (2/4), 241-253.

(3) Prikryl, J. D.; Pabalan, R. T.; Turner, D. R.; Leslie, B. W. Uranium sorption on a-alumina: effects of $\mathrm{pH}$ and surface area/solution volume ratio. Radiochim. Acta 1994, 66/67, 291-296.

(4) Davis, J. A.; Meece, D. E.; Kohler, M.; Curtis, G. P. Approaches to surface complexation modeling of uranium (VI) adsorption on aquifer sediments. Geochim. Cosmochim. Acta 2004, 68 (18), $3621-3641$.

(5) Waite, T. D.; Davis, J. A.; Payne, T. E.; Waychunas, G. A.; Xu, N. Uranium (VI) adsorption to ferrihydrite: Application of a surface complexation model. Geochim. Cosmochim. Acta 1994, 58 (24), 5465-5478.

(6) Hsi, D. C.; Langmuir, D. Adsorption of uranyl onto ferric oxyhydroxides: application of the surface complexation sitebinding model. Geochim. Cosmochim. Acta 1985, 49 (9), 19311941.

(7) Turner, G. D., Zachara, J. M.; McKinley, J. P.; Smith, S. C. Surfacecharge properties and $\mathrm{UO}_{2}{ }^{2+}$ adsorption of a subsurface smectite. Geochim. Cosmochim. Acta 1996, 60 (18), 3399-3414.

(8) McKinley, J. P.; Zachara, J. M.; Smith, S. C.; Turner, G. D. The influence of uranyl hydrolysis and multiple site binding reactions on adsorption of U(VI) to montmorillonite. Clays Clay Miner. 1995, 43 (5), 586-598.

(9) Payne, T. E.; Davis, J. A.; Lumpkin, G. R.; Chisari, R.; Waite, T. D. Surface complexation model of uranyl adsorption on Georgia kaolinite. Appl. Clay Sci. 2004, 26 (1/4), 151-162.

(10) Chisholm-Brause, C. J.; Berg, J. M.; Matzner, R. A.; Morris, D. E. Uranium (VI) sorption complexes on montmorillonite as a function of solution chemistry. J. Colloid Interface Sci. 2003, 233 (1), 38-49.

(11) Chisholm-Brause, C. J.; Berg, J. M.; Little, K. M.; Matzner, R. A.; Morris, D. E. Uranium sorption by smectites: spectroscopic assessment of thermodynamic modeling. J. Colloid Interface Sci. 2004, 277 (2), 366-382.

(12) Kowal-Fouchard, A.; Drot, R.; Simoni, E.; Ehrhardt, J. J. Use of spectroscopic techniques for uranium(VI)/montmorillonite interaction modeling. Environ. Sci. Technol. 2004, 38 (5), 13991407.

(13) Reich, T.; Moll, H.; Arnold, T.; Denecke, M. A.; Hennig, C.; Geipel, G.; Bernhard, G.; Nitsche, H.; Allen, P. G.; Bucher, J. J.; Edelstein, N. M.; Shuh, D. K. An EXAFS study of uranium (VI) sorption onto silica gel and ferrihydrite. J. Electron Spectrosc. Relat. Phenom. 1998, 96 (1/3), 237-243.

(14) Morris, D. E.; Chisholm-Brause, C. J.; Barr, M. E.; Conradson, S. D.; Eller, P. G. Optical spectroscopic studies of the adsorption of $\mathrm{UO}_{2}{ }^{2+}$ species on a reference smectite. Geochim. Cosmochim. Acta 1994, 58 (17), 3613-3623.

(15) Chisholm-Brause, C.; Conradson, S. D.; Buscher, C. T.; Eller, P. G.; Morris, D. E. Speciation of uranyl sorbed at multiple binding sites on montmorillonite. Geochim. Cosmochim. Acta 1994, 58 (17), 3625-3631.

(16) Hennig, C.; Reich, T.; Dähn, R.; Scheidegger, A. M. Structure of uranium sorption complexes at montmorillonite edge sites. Radiochim. Acta 2002, 90, 653-657.

(17) Sylvester, E. R.; Hudson, E. A.; Allen, P. G. The structure of uranium (VI) sorption complexes on silica, alumina and montmorillonite. Geochim. Cosmochim. Acta 2000, 64 (14), 2431-2438.

(18) McGlynn, S. P.; Smith, J. K.; Neely, W. C. Electronic structure, spectra and magnetic properties of oxycations. III. Ligation effects on the infrared spectrum of the uranyl ions. J. Chem. Phys. 1961, 35 (1), 105-116.

(19) Bell, J. T.; Biggers, R. E. The absorption spectrum of the uranyl ion in perchlorate media. II. The effects of hydrolysis on the resolved spectral bands. J. Mol. Spectrosc. 1967, 22 (1/4), 262271. 
(20) De Houwer, S.; Servaes, K.; Goerller-Walrand, C. On the site symmetry of uranyl crown compounds in solution. Phys. Chem. Chem. Phys. 2003, 5 (6), 1164-1168.

(21) Baird, C.; Kemp, T. J. Luminescence spectroscopy, lifetimes and quenching mechanisms of excited states of uranyl and other actinide ions. Prog. React. Kinet. 1997, 22 (1), 87-139.

(22) Kitamura, A.; Yamamura, T.; Hase, H.; Yamamoto, T.; Moriyama, $H$. Measurements of hydrolysis of species of U(VI) by timeresolved laser induced fluorescence spectroscopy. Radiochim. Acta 1998, 82 (1), 147-152.

(23) Clark, D. I.; Conradson, S. D.; Donohoe, R. J.; Keogh, D. W.; Morris, D. E.; Palmer, P. D.; Rogers, R. D.; Drew, C. D. Chemical speciation of the uranyl ion under highly alkaline conditions. Synthesis, structures and oxo ligand exchange dynamic. Inorg. Chem. 1999, 38 (7), 1456-1466.

(24) Moulin, C.; Decambox, P.; Moulin, V.; Decaillon, J. G. Uranium speciation in solution by time-resolved laser-induced fluorescence. Anal. Chem. 1995, 67 (2), 348-353.

(25) Kato, Y.; Meinrath, G.; Kimura, T.; Yoshida, Z. A study of U (VI) hydrolysis and carbonate complexation by time-resolved laserinduced fluorescence spectroscopy (TRLIFS). Radiochim. Acta 1994, 64 (1), 107-111.

(26) Moll, H.; Geipel, G.; Brendler, V.; Bernhard, G.; Nitsche, H. Interaction of uranium (VI) with silicic acid in aqueous solution studied by time-resolved laser-induced fluorescence spectroscopy (TRLIFS). J. Alloys Compd. 1998, 271/273, 765-768.

(27) Eliet, V.; Grenthe, I.; Bidoglio, G. Time-resolved laser-induced fluorescence of uranium (VI) hydroxo complexes at different temperatures. Appl. Spectrosc. 2000, 54 (1), 99-105.

(28) Duff, M. C.; Morris, D. E.; Hunter, D. B.; Bertsch, P. M. Spectroscopic characterization of uranium in evaporation basin sediments. Geochim. Cosmochim. Acta 2000, 64 (9), 1535-1550.

(29) Hunter, D. B.; Bertsch, P. M. In situ examination of uranium contaminated soil particles by micro-X-ray absorption and micro-fluorescence spectroscopies. J. Radioanal. Nucl. Chem. 1998, 234 (1/2), 237-242.

(30) Lomenech, C.; Simoni, E.; Drot, R.; Ehrhardt, J. J.; Mielczarski, J. Sorption of uranium (VI) species on zircon: structural investigation of the solid/solution interface. J. Colloid Interface Sci. 2003, 261 (2), 221-232.

(31) Geipel, G.; Bernhard, G.; Brendler, V.; Nitsche, H. Sorption of uranium (VI) on rock material of a mine tailing pile. Solution speciation by fluorescence spectroscopy. Radiochim. Acta 1996, $74,235-238$.

(32) Gabriel, U.; Charlet, L.; Schläpfer, C. W.; Vial, J. C.; Brachmann, A.; Geipel, G. Uranyl surface speciation in silica particles studied by time-resolved laser-induced fluorescence spectroscopy. J. Colloid Interface Sci. 2001, 239 (2), 358-368.

(33) Wang, Z.; Zachara, J. M.; Yantasee, W.; Gassman, P. L.; Liu, C. X.; Joly, A. G. Cryogenic laser induced fluorescence characterization of U(VI) in Hanford vadose zone pore waters. Environ. Sci. Technol. 2004, 38 (21), 5591-5597.

(34) Wang, Z.; Zachara, J. M.; Yantassee, W.; Gassman, P. L.; Joly, A. G.; Catalano, J. Fluorescence spectroscopy of U(VI)-silicates and U(VI)-contaminated Hanford sediment. Geochim. Cosmochim. Acta 2005, 69 (6), 1391-1403.

(35) Baumann, N.; Brendler. V.; Arnold, T.; Geipel, G.; Bernhard, G. Uranyl sorption on gibbsite studied by time-resolved laserinduced fluorescence spectroscopy (TRLFS). J. Colloid Interface Sci. 2005, 290 (2), 318-324.

(36) Meinrath, G.; Schweinberger, M. Hydrolysis of the uranyl(VI) ion-A chemometric approach. Radiochim. Acta 1996, 75 (1), 205-210.

(37) Moulin, C.; Charron, N.; Plancque, G.; Virelizier, H. Speciation of uranium by electrospray ionization mass spectrometry: comparison with time-resolved laser-induced fluorescence. Appl. Spectrosc. 2000, 54 (6), 843-848.

(38) Hiemstra, T.; Yong, H.; Van Riemsdijk, W. H. Interfacial charging phenomena of aluminum (hydr)oxides. Langmuir 1999, 15, (18), 5942-5955.

(39) Weerasooriya, R.; Dharmasena, B.; Aluthpatabendi, D. Coppergibbsite interactions: an application of 1-pK surface complexation model. Colloids Surf., A 2000, 170, 65-77.

(40) Stumm, W.; Morgan, J. J. Aquatic Chemistry. Chemical Equilibria and Rates in Natural Waters; John Wiley and Sons: New York, 1996.

(41) Dzombak, D. A.; Morel, F. M. M. Surface Complexation Modeling. Hydrous Ferric Oxide; John Wiley and Sons: New York, 1990

(42) Grenthe. I.; Fuger, J.; Konings, R. J. M.; Lemire, R. J.; Muller, A B.; Nguyen-Trung, C.; Wanner, H. Chemical thermodynamics of uranium; Nuclear Energy Agency Organisation for Economic Co-Operation and Development: Issy-les-Moulineaux, France, 2004 (http://www.nea.fr/html/dbtdb/pubs/uranium.pdf).

Received for review August 29, 2005. Revised manuscript received December 16, 2005. Accepted December 19, 2005.

ES051714I 